\title{
TONE CURVE RECONSTRUCTION ALGORITHM FOR AUTOMATING CREATION OF AEROSPACE IMAGES
}

\author{
Irina Artyushina ${ }^{1}$, Aleksey Vinokur ${ }^{1,2}$, Vitaly Krupenin ${ }^{1,3}$ \\ ${ }^{1}$ Moscow Polytechnic University, Russia; ${ }^{2}$ National Research Nuclear University MEPhI (Moscow \\ Engineering Physics Institute), Russia; ${ }^{3}$ IMASH RAN, Russia \\ i.1.artyushina@mospolytech.ru, a.i.vinokur@mospolytech.ru,krupeninster@gmail.com
}

\begin{abstract}
In the paper we discuss the technical aspects of creating a map of a large section of the earth surface by matching the sequence of elementary shots. We present an algorithm for reconstructing a tone curve of the sensor necessary to harmonize the areas of the map in brightness and contrast. The input data are the images of a surface area, which differ in brightness due to different exposure conditions. The algorithm efficiency is confirmed by a practical recovery of a digital picture. The obtained function can be used to ensure correct (without diviation) tone rendering of the objects of shooting. The algorithm is recommended to automate the creation of aerospace images of industrial and agricultural objects.
\end{abstract}

Keywords: tone curve, aerospace shooting, image stitching, exposure, tone rendering, HDRI.

\section{Introduction}

Aerospace images of the earth surface are widely used in territory and transport management, as well as in agriculture, when dealing with fires or floods, harvest forecasting, analyzing the situations on roads and railroads, etc.

Photos are taken from planes, helicopters, satellites and so on. The result is a map that is an image of a large area of the earth surface. The map is created from many images, each having its own brightness and scale. For image stitching, they must be adjusted ensuring consistency in scale, sharpness, tone and color. These tasks are based on the tone curve, i.e. the properties of a sensor's response to the different brightness areas of the object [1;2]. The standard data do not often correspond to the actual shooting conditions, or they are simply missing.

When shooting wide-angle and high-contrast objects, the closest tasks are creating panoramas and using the High Dynamic Range Imaging (HDRI) technology. Panning solves the problem of stapling and combining the parts, and the HDRI technology allows to align images in brightness and provide the detail elaboration. However, to ensure the accurate ratios of brightness in a space image, the knowledge of the tone curve is required [3]. There are not any algorithms of defining this characteristic of the shooting process. In this article, a specific algorithm for creating a tone curve is proposed.

\section{Model and methods}

Recording of the digital image of the earth surface is performed using a matrix or a line containing photosensitive elements. Each of them is described by a tone characteristic, which is assumed to be the same for all the elements. The effect-exposure relationship is commonly called the characteristic curve (for simplicity we assume that the photographic effect is described by some color coordinate). At a fixed exposure, the relationship of the photographic effect versus the brightness of the object is commonly called the tone curve $[4 ; 6]$. When solving the direct problem, the tone curve is considered as preset. In our case the inverse problem is being solved, so the tone curve is to be found.

As input data, we have two pictures of soft hearth surface, taken with different exposures. In other words, we have the information about the value of the color coordinate for each pixel in the image. The mechanism of digital image formation is clear from Figure 1.

The logarithm of the pixel brightness $\lg Y$ was selected as the color coordinate. The choice of the color coordinate is a fundamental matter. The fact is that in the model of image formation we use the characteristic curve of the sensor, and operate on two variables: the color coordinate and the logarithm of exposure. In fact, no direct (measured) data on the logarithm values of the exposure are available to us. The challenge is to calculate the values of the exposure logarithms for each color coordinate by the values of the two image color coordinates. That is, to create the tone curve as the dependence of the color coordinate of the picture on the color coordinate of the corresponding portion of the earth surface. The advantage of the chosen logarithmic values is the easy interpretation of the addition and 
subtraction operations. The other values used in colorimetry (brightness, gamma converted color coordinates and so on) do not have this property.

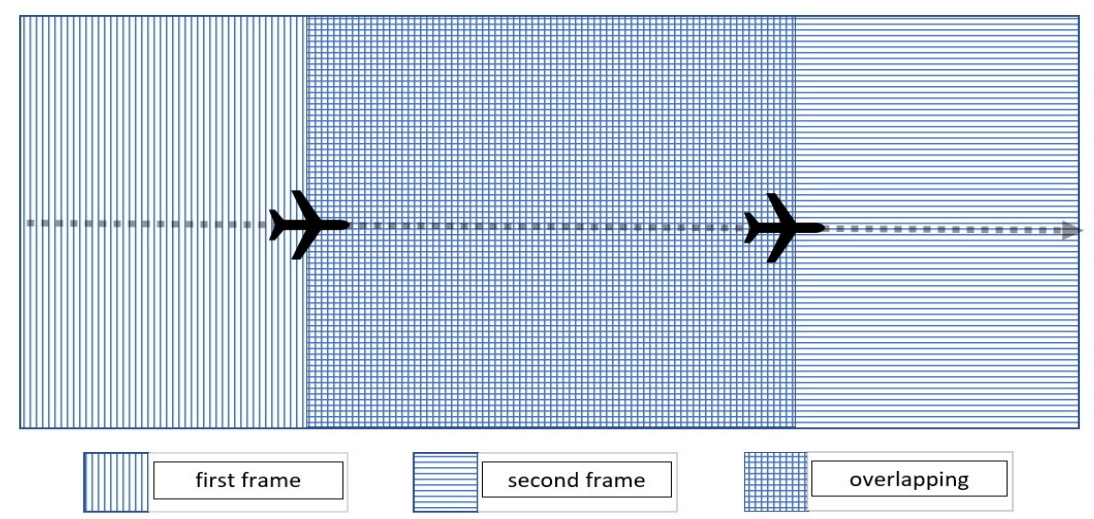

Fig. 1. Shooting scheme

Let us begin with the solution of the direct problem. Suppose $y=f(x)$ is a characteristic curve of the sensor, expressed as logarithms of brightness; $x$ is the logarithm of brightness of the earth surface plot; $y$ is the logarithm of brightness of the corresponding pixel of the image; $z$ is the exposure parameter, expressed as logarithms of exposure.

$$
\begin{aligned}
& y^{(1)}=f\left(x+z_{1}\right) \\
& y^{(2)}=f\left(x+z_{2}\right)
\end{aligned},
$$

where $z_{1}$ - first frame exposure parameter;

$z_{2}-$ second frame exposure parameter.

A typical characteristic curve usually has a so-called straight line segment, on which the function $f$ can be approximated by a linear function. When the difference of exposure $z_{1}$ and $z_{2}$ is small, it is natural to expect that there will be a set of pixels, the values of which of logarithm brightness for both images lie on the straight line segment. This will allow us to write equations for estimating the exposure shift.

$$
\begin{aligned}
& y^{(1)}=\gamma\left(x+z_{1}\right)+b \\
& y^{(2)}=\gamma\left(x+z_{2}\right)+b
\end{aligned},
$$

where $\gamma$-contrast parameter;

$$
b-\text { constant. }
$$

Subtracting the first equation from the second one, and solving it for $z_{2}-z_{1}$, we have:

$$
z_{2}-z_{1}=\frac{1}{\gamma}\left(y^{(2)}-y^{(1)}\right),
$$

Thus, with accuracy up to the multiplier gamma, the exposure shift can be calculated from the experimental data. This allows us to draw the tone curve.

\section{The sequence of actions}

First, the area for the digital image is allocated. This area is the image of the same earth surface plot on the two pictures. We believe that with modern methods and software for processing aerospace images, pixel-by-pixel combining is not an issue $[1,6]$. Generally, there is a difference in brightness between the first and the second images due to the change in the exposure conditions of the shot [5].

The heterogeneity of the object (for example, fine detail and contours), should not affect the solving of the tone mapping task. So, the next step is preliminary and consistent processing of both images aimed at selecting (detection) the pairs of pixels that lie in the regions of smooth variation of 
brightness. This can be done by frequency filtering, or by selecting areas possessing a slight change in brightness, by removing the sections with fine details and contours [1; 4; 7-9].

Then we proceed to processing the remaining information. It is assumed that each pixel is encoded in the coordinates of the RGB. If we consider the $X Y Z$ coordinates, it is essential here that the source encoding usually has 256 levels. However, we must move to a representation in the form of floating-point calculations to avoid large loss of accuracy and even errors. We select the coordinate responsible for the brightness, in accordance with the previously described model [10], take its logarithm and normalize it.

For each point of the digital image we generate a couple of logarithm values of brightness. The first value refers to the image with less exposure, while the second one refers to that with more. A number is assigned to each couple, which allows us to sort the sequence of couples. The following conditions are required:

$$
y_{k}^{(1)} \leq y_{k+1}^{(1)} \& y_{k}^{(2)} \leq y_{k+1}^{(2)},
$$

where $k$-number of couple.

The points with equal couples of values are identified and included in the sequence only once. Thus we obtain an ordered sequence of couples of brightness in logarithmic form.

Figure 2 shows a plan of the formation of two logarithmic brightness sequences. The upper curve corresponds to a larger exposure, the lower corresponds to a smaller one. To obtain a tone curve we shift the upper curve to the right so that its straight portion is aligned with the straight portion of the bottom curve. Thus, we obtain a tone curve. The interval of the argument change is equal to the sum of the maximum value of the logarithm brightness and the exposure shift.
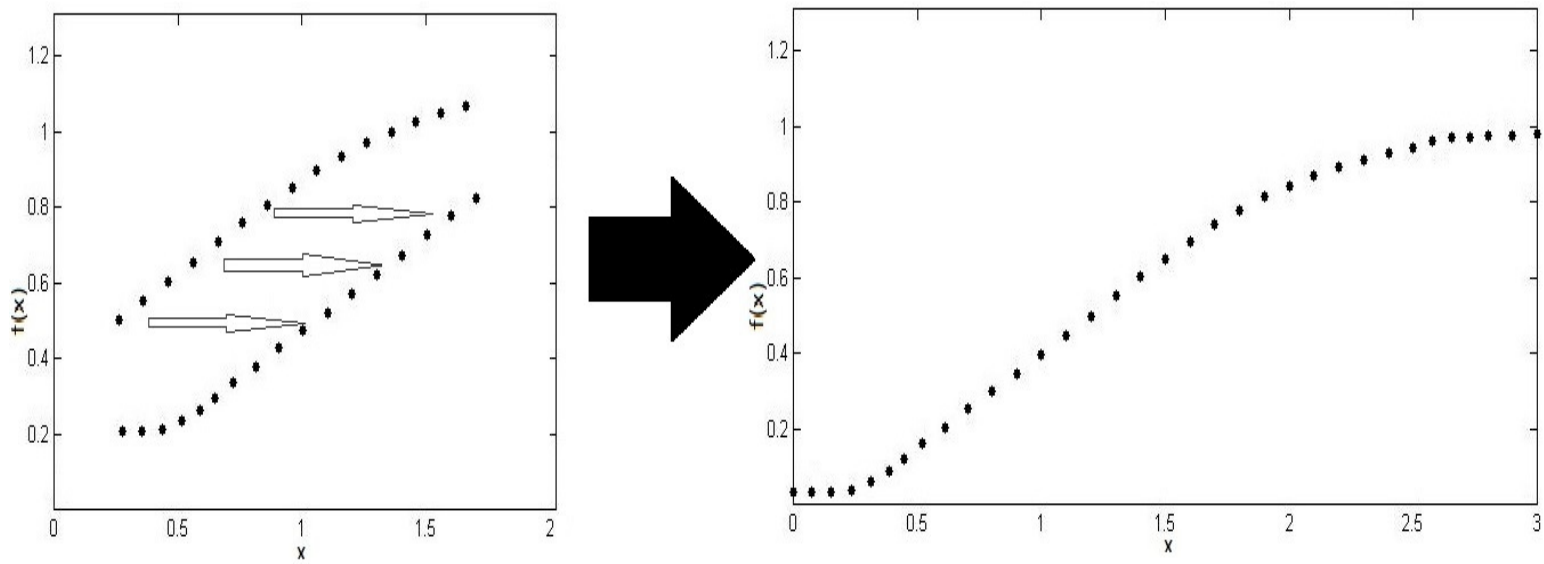

Fig. 2. Plan of formation of two logarithmic brightness sequences and tone curve

The sequence of operations is given in Figure 3.

\section{Results and discussion}

To check the proposed algorithm, an aerial photograph of Casper Kowalski (URL: http://www.anzenbergergallery.com/category/landscape) is used. Figure 4 shows the two images of the same area of the earth surface taken with different exposures. Figure 5 shows the histograms of the logarithm values of brightness for each image. The histograms allow us to determine the maximum and minimum values of the logarithms of the two images. Their difference equals to the dynamic range of the tone curve within the accuracy of a constant multiplier gamma. In our case, the dynamic range is normalized to 1.0 logarithmic units.

Figure 6 shows the typical joint distribution of the logarithm brightness values $y^{(1)}$ and $y^{(2)}$ presented as a set of points, each corresponding to one pixel of the digital image of the investigated area of the earth surface. This distribution allows us to estimate the difference between the exposures of the two images of $\gamma\left(z_{2}-z_{1}\right)$ as the maximum deviation from the straight line $y^{(1)}=y^{(2)}$. In our case, in logarithmic units, it is equal to 0.24 logarithmic units. 
The obtained tone curve $f r(x)$ is given in Figure 7. With its help, the image of the earth surface was created by using two pictures. We compared the obtained curve with the one used in practice, after adjusting the dynamic ranges of both curves. The standard deviation is equal to 0.02 . This suggests a high accuracy of the proposed algorithm.

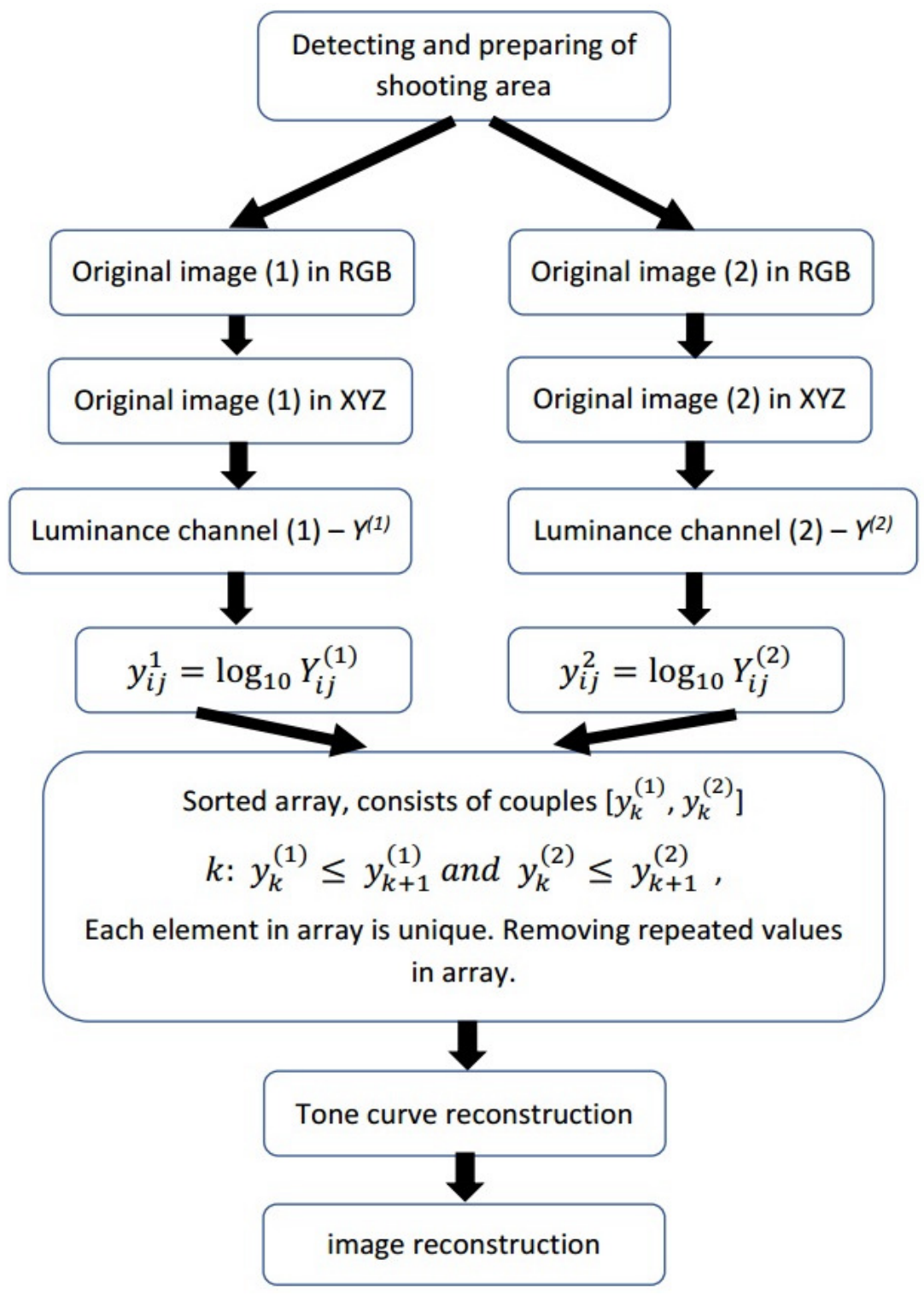

Fig. 3. Sequence of operations
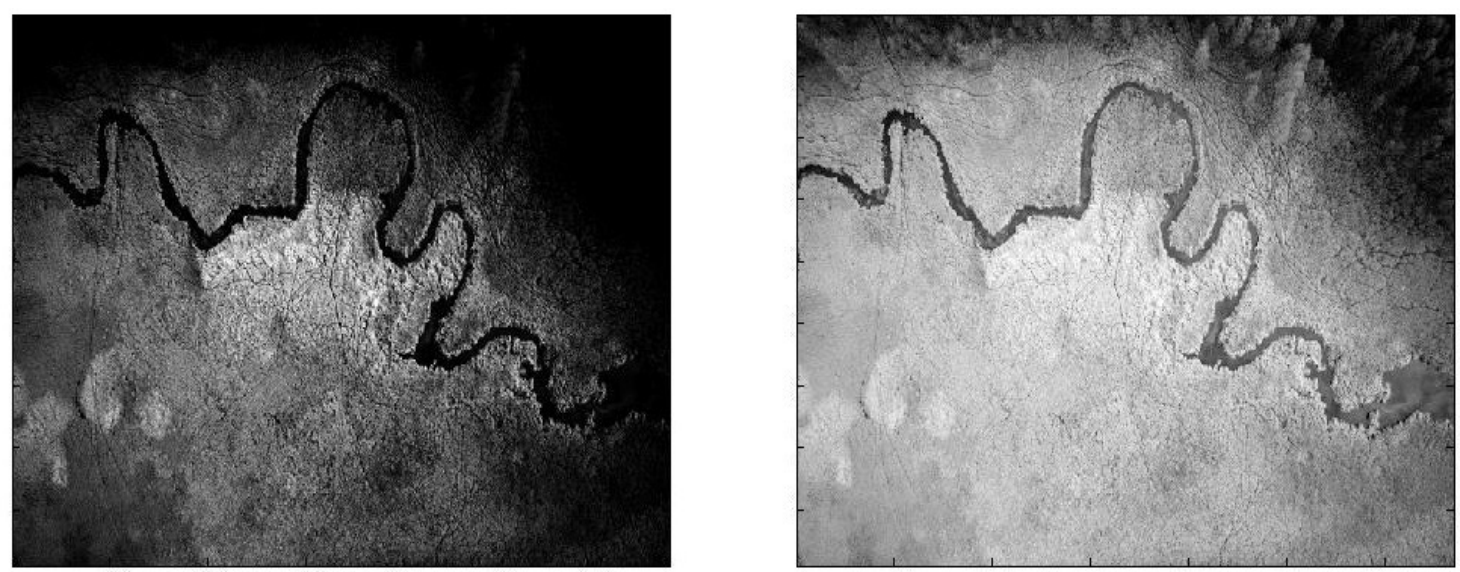

Fig. 4. Two images of the same area of the earth surface 


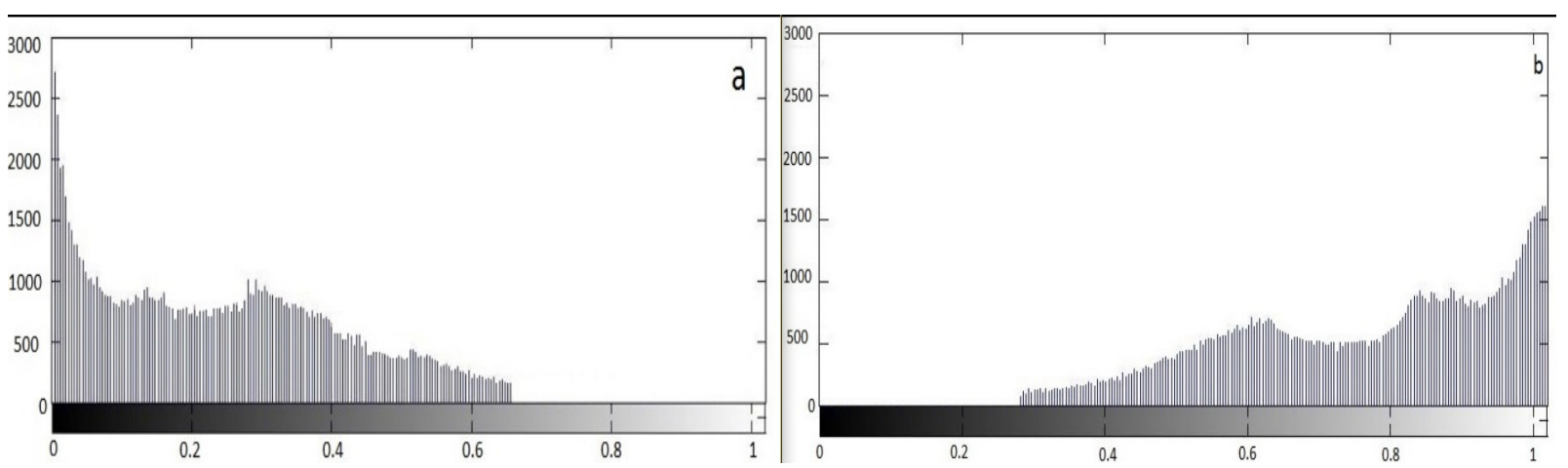

Fig. 5. Histograms of logarithm values of brightness: a - refers image with less exposure; $\mathrm{b}$ - refers image with more exposure

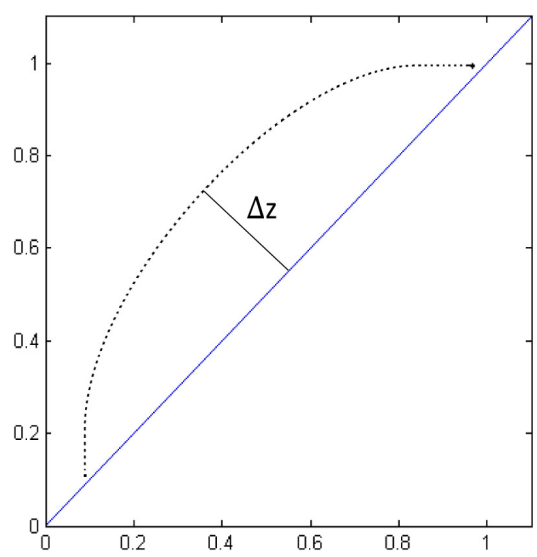

Fig. 6. Typical distribution of couples of logarithm values of brightness first and second shoots in the coordinates $\boldsymbol{y}^{(1)}, \boldsymbol{y}^{(2)}: \Delta z-$ exposure shift
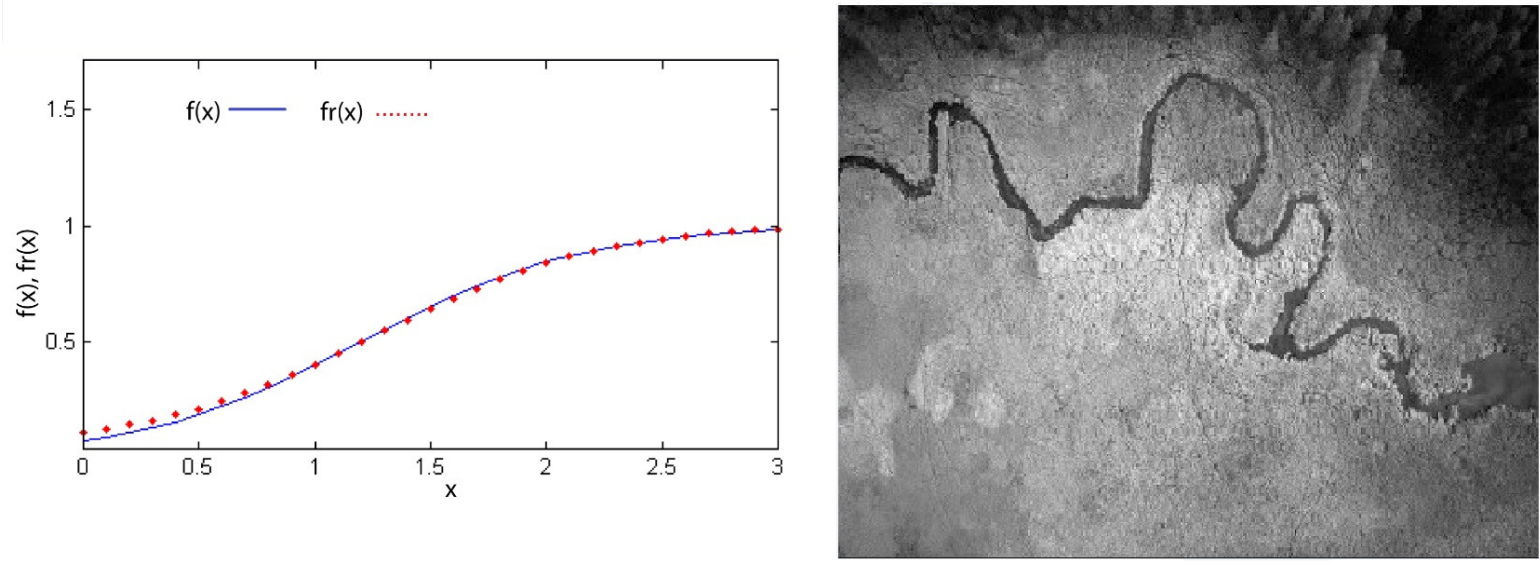

Fig. 7. Reconstructed tone curve and reconstructed image of the earth surface

\section{Conclusions}

The algorithm analysis shows, that to obtain a correct result the images must contain the minimum and the maximum brightness of the dynamic range, also the intervals of brightness changes of the images must cover the entire dynamic range. In practice, we can have more than two images. To build the tone curve, the minimal set should be chosen that satisfies the formulated conditions. In detail the computational part of the algorithm is analyzed in [5]. The algorithm of a tone curve creation for aerospace shooting has been developed. The calculations are based on processing two digital images of the earth surface, differing in brightness level due to different exposure conditions of shooting. No additional information on the light sensitive properties of the sensor is available, so the construction can be carried out within the accuracy of a multiplier. This feature does not reduce the 
usefulness of the result, as the obtained digital image, at any visualization process, requires matching the dynamic ranges of registration and visualization systems. The obtained function can be used to ensure correct (without distortion) tone rendering of registered objects. Experimental testing confirms the effectiveness of the approach. The algorithm is recommended to automate the creation of aerospace images.

\section{Acknowledgement}

The authors are grateful to A.V. Glazkov for his assistance and valuable comments.

\section{References}

1. Reinhard E., Ward G., Pattanaik S. and Debevec P. High Dynamic Range Imaging: Acquisition, Display and Image-Based Lighting. San Francisco: Morgan Kaufmann Publisher, 2006, 522 p.

2. Takao J., Masahiro O. Multiple Exposure Fusion for High Dynamic Range Image Acquisition. IEEE Transactions on image processing, vol. 21, No. 1, January 2012 pp 358-365

3. Salih Y., Malik A. A Comparative Study of Various Tone Mapping Methods. International Journal of Computer, Electrical, Automation, Control and Information Engineering, 2011, vol. 5, No. 10, pp 1121-1126

4. Vinokur A.I. Information Technologies in Culture and Education: Image Processing Issues. Modern Applied Science, vol. 9(5), 2015, pp. 314-322.

5. Akhtariev R., Vinokur A. Quality evaluation algorithms for HDR image generation. Printing future days, 2011, Chemnitz, Germany, pp 171-175

6. Чибучичев Л.Г., Финошин Д.Л. Метод создания условного кадра, состоящего in множества микрокадров, полученных съемочными системами «Канопус-В» и БКА. (Method of creating reference frame consisting of microframes, obtained from «Kanopus-V» and BKA survey systems). Proceedings of the institutions of higher education. Geodesy and aerial photography: Известия высших учебных заведений. Геодезия и аэрофотосъемка, 2015, No. 6, pp. 48-52 (In Russian)

7. Артюшина И.Л., Винокур А.И. Информационные системы: проблемы регистрации и воспроизведения изображений. (Information systems: image recording and visualization problems). Proceedings of the institutions of higher education. Issues of the graphic arts and publishing: Известия высших учебных заведений. Проблемы полиграфии и издательского дела, 2011, No 4, pp. 75-82 (In Russian)

8. Артюшина И.Л., Винокур А.И., Ноздрачёв С.А. Алгоритм согласования динамических диапазонов в информационных системах обработки изображений. (Algorithm for matching dynamic ranges in information processing systems of images) World of Technique of Cinema: Мир техники кино, 2012, No 26, pp. 25-27 (In Russian)

9. Артюшина И.Л., Ахтариев Р.Ж., Винокур А.И. Методы регистрации и воспроизведения высококонтрастных оригиналов в системах с ограниченным динамическим диапазоном (Methods for recording and reproducing high-contrast originals in systems with a limited dynamic range). Proceedings of the institutions of higher education. Issues of the graphic arts and publishing: Известия высших учебных заведений. Проблемы полиграфии и издательского дела, 2009, No 4, pp. 9-15 (In Russian)

10. Артюшина И.Л., Винокур А.И., Крупенин В.Л. К проблеме восстановления характеристической кривой регистрирующего устройства. (То the problem of recovering the characteristic curve of the recording device). Bulletin of scientific and technical development: интернет-журнал "Вестник научно-технического развития", 2015, No 8(96), pp. 11-17 (In Russian). 